\title{
Socioeconomic position and prediagnostic health care contacts in children with cancer in Denmark: a nationwide register study
}

Line Hjøllund Pedersen ${ }^{1,2^{*}}$, Friederike Erdmann ${ }^{3}$, Gitte Lerche Aalborg ${ }^{4}$, Lisa Lyngsie Hjalgrim? , Hanne Bækgaard Larsen ${ }^{1,5}$, Kjeld Schmiegelow ${ }^{1,5}$, Jeanette Falck Winther ${ }^{6}$ and Susanne Oksbjerg Dalton $2,5,7$

\begin{abstract}
Background: While underlying mechanisms and pathways of social inequalities in cancer survival have been extensively examined in adults, this is less so for children with cancer. Hypothesized mechanisms include prediagnostic utilization of and navigation through the health care system, which may differ by socioeconomic resources of the families. In this nationwide register-based study we investigated the association between measures of family socioeconomic position in relation to prediagnostic health care contacts and stage of disease at diagnosis in children with cancer in Denmark.
\end{abstract}

Methods: We identified all children diagnosed with a cancer at ages 0-15 years in 1998-2016 ( $N=3043)$ from the Danish Childhood Cancer Registry. We obtained comprehensive information on measures of socioeconomic position, parental health and prediagnostic contacts to both general practitioners and hospitals 24 months prior to diagnosis from various national registries. We fitted multivariable conditional logistic regression models for the association of family socioeconomic and health-related variables with firstly, frequent health care contacts and secondly, advanced stage.

Results: We found higher odds ratios (OR) of frequent both overall and emergency health care contacts in the last 3 months before diagnosis in children from households with short parental education and mixed affiliation to work market, when compared to children with high family socioeconomic position. Further, children of parents with depression or of non-Western origin, respectively, had higher OR for frequent overall and emergency contacts. We found no association between socioeconomic position, parental health and stage of disease.

Conclusion: Families with socioeconomic disadvantage, non-Western origin or depression more frequently utilize prediagnostic health care services, both generally and in the acute setting, indicating that some disadvantaged families may struggle to navigate the health care system when their child is sick. Reassuringly, this was not reflected in disparities in stage at diagnosis. In order to improve the diagnostic process and potentially reduce health care contacts, attention and support should be given to families with a high number of health care contacts over a short period of time.

Keywords: Childhood, Childhood cancer, Socioeconomic position, Social inequality, Prediagnostic contacts, Denmark, Register study, Diagnosis, Stage

\footnotetext{
* Correspondence: lipe@cancer.dk

'Department of Paediatrics and Adolescent Medicine, Rigshospitalet, Copenhagen, Denmark

${ }^{2}$ Survivorship and Inequality in Cancer, Danish Cancer Society Research Center, Copenhagen, Denmark

Full list of author information is available at the end of the article
}

C C The Author(s). 2021 Open Access This article is licensed under a Creative Commons Attribution 4.0 International License, which permits use, sharing, adaptation, distribution and reproduction in any medium or format, as long as you give appropriate credit to the original author(s) and the source, provide a link to the Creative Commons licence, and indicate if changes were made. The images or other third party material in this article are included in the article's Creative Commons licence, unless indicated otherwise in a credit line to the material. If material is not included in the article's Creative Commons licence and your intended use is not permitted by statutory regulation or exceeds the permitted use, you will need to obtain permission directly from the copyright holder. To view a copy of this licence, visit http://creativecommons.org/licenses/by/4.0/ The Creative Commons Public Domain Dedication waiver (http://creativecommons.org/publicdomain/zero/1.0/) applies to the data made available in this article, unless otherwise stated in a credit line to the data. 


\section{Background}

Although survival from childhood cancer has improved substantially over the past five decades [1], cancer remains the leading cause of disease-related deaths among 1-15 years olds in Europe [2]. Not all children benefit equally from the recent diagnostic and therapeutic improvements and large survival disparities have been observed across countries [1] as well as within countries, including European countries [3, 4] and specifically also Denmark [5], where equal access to health care services irrespective of socioeconomic position (SEP) is presumed. Lower survival has been demonstrated for children of families where parents have short education [5-7], low income [8], are single [5, 9] and have poor living conditions [10] as well as for children with siblings $[5,7,11]$ and of higher birth order [11], compared to children from more advantaged families. While underlying mechanisms and pathways of social inequalities in cancer have been extensively assessed in adults, this does not hold true for childhood cancer. Despite the significant public health relevance, the underlying mechanisms of these empirically demonstrated survival inequalities in children with cancer remain poorly understood.

One hypothesized mechanism contributing to socioeconomic differences in survival refers to differences in the families social resources and coping behavior [1214], health literacy as well as communication skills and barriers with health professionals [15-17] which may lead to differential delay in diagnosis [18]. Delay in diagnosis may be reflected in a more frequent use of health care contacts, leading to more advanced disease and potentially poorer outcome. In Denmark, general practitioners (GP) are important gatekeepers to diagnosis and treatment $[19,20]$. Studies have shown a high utilization of primary care services in the prediagnostic period of children with cancer [18-20] as well as a social gradient in the utilization of GP before diagnosis $[18,19]$. Beside GPs, GPs on call (emergency doctors) and emergency units may be important gatekeepers to diagnosis [21]. However, particularly the utilization of emergency services or hospital contacts in the prediagnostic period are poorly assessed for children with cancer, and such evidence may contribute to a better understanding of the causal mechanisms and pathways of social inequities in childhood cancer survival.

Stage at diagnosis is a strong predictor for cancer survival in both adult and childhood cancer [22-24]. The evidence on the prognostic impact of time to diagnosis of childhood cancer is inconsistent and heterogeneous across cancer types [25], but is of significant concern as early diagnosis may still prevent progression and secure less extensive treatment. More advanced disease at diagnosis requiring a greater burden of cancer therapy in children with Wilms tumor was observed in the UK, where the health care system is also characterized by GPs acting as gatekeepers to specialized health care [26]. In a recent review, Mogensen et al. [3] suggested a potential association between SEP and advanced stage of disease at diagnosis [23, 27, 28] but emphasized that findings were contradictory [22, 29, 30]. To our knowledge, no previous study has addressed the association between SEP, prediagnostic health care contacts and stage at diagnosis in children with cancer. In this nationwide study, we took advantage of the high-quality registry data of Denmark to examine the association between SEP and the number of health care contacts during the 24 months prior to a childhood cancer diagnosis with a particular focus on the last 3 months before diagnosis. Moreover, in a subpopulation, we assessed the association between SEP and stage of disease at diagnosis and examined whether number of health care contacts may mediate such an association.

\section{Methods}

Denmark has a population-based register infrastructure with long-standing administrative registries with highquality health and socioeconomic data and a unique personal identification number used in all registries [31] that enables individual linkage of information across registries. Linkage of information across registries provided the basis for our nationwide register study.

\section{Study design and population}

We identified all incident cases of cancer diagnosed in children aged 0-15 years in 1998-2016 in Denmark from the Danish Childhood Cancer Registry (DCCR) [32]. The DCCR is a nationwide clinical quality database set up to monitor the quality of childhood cancer care in Denmark. For each child with cancer, we obtained information on date of diagnosis, diagnosis code and stage of disease from the DCCR. Diagnoses were coded according to the International Classification of Childhood Cancer third version (ICCC-3) into 12 major diagnostic groups. We defined the following five cancer groups based on the ICCC-3 major diagnostic groups [33]: Leukemias, myeloproliferative diseases, and myelodysplastic diseases (Leukemia), Lymphomas and reticuloendothelial neoplasms (Lymphoma), CNS and miscellaneous intracranial and intraspinal neoplasms (CNS tumors), Malignant bone tumor and soft tissue and other extraosseous sarcomas (Bone tumors and soft tissue sarcomas), and other non-CNS solid tumors. With this grouping, we aggregated cancer types with similar characteristics into groups of larger sample sizes to increase statistical power, while keeping distinct diagnostic groups separate for meaningful analysis. 


\section{Socioeconomic position of the household}

By using the personal identification number from the Danish Civil Registration System [31], we were able to identify the respective household for each child and the parents they were living with at time of diagnosis. In the following denoted as household parents regardless of biological relationship.

Information from the social registries administered at Statistics Denmark were used to define the SEP of the household [34-36]. SEP is a multidimensional construct and determined by various indicators measuring different aspects of economic and social resources, assets and conditions [37]. Indicators of SEP included highest parental education in the household categorized into short ( $<10$ years, primary and lower secondary education), medium (10-12 years, upper secondary and vocational) and long education (>12 years, higher education); household cohabitation status categorized into parents living together or living alone; highest parental annual disposable income categorized into quintiles (based on the sex, birth cohort and calendar year-specific income distribution of the entire Danish population); household affiliation to work market categorized into at work, unemployed/not in work force and mixed (household parents belong to different categories); country of origin for household parents categorized into Denmark, Western country, non-Western country and mixed (household parents belong to different categories); number of children in household categorized into one, two or three or more. Information on education, income, affiliation to the work market were obtained the year prior to diagnosis and for cohabitation status and number of children for the year of diagnosis.

\section{Health of the household parents}

We obtained information on chronic somatic diseases included in the Charlson Comorbidity Index [38] and diagnosis of a major psychiatric disorder (not including depression) (ICD-8: 290 to 295.99, 296.19, 296.39, 303.00-304.99 and ICD-10: F00-F31) in the household parents for the 5 years prior to the child's cancer diagnosis from the Danish National Patient Register (NPR) [39] and the Danish Psychiatric Central Research Register [40] and created a variable for somatic or major psychiatric disease in household parents, categorized as yes (one or more disease) or no (none). We further included information from the Danish National Prescription Registry [41] to create a variable describing depression in the household parents during 2 years prior to the cancer diagnosis (yes/no) based on any redeemed prescription for antidepressants (ATC-group N06A) or any diagnosis of unipolar depression (ICD-8: 296.09, 296.29 or ICD-10: F32-F33.9).

\section{Health care contacts}

The Danish National Health Service Register holds information on all contacts and procedures/services in the primary health care sector in Denmark since 1990 [42], while the NPR has registered all hospital admissions since 1978 and outpatient and emergency contacts since 1994 [39]. Information on all health care contacts including date and contact type were collected for 24 months prior to the child's diagnosis. From the Danish National Health Service Register, we collected all GP contacts including face-to-face, e-mail consultations and home visits. Contacts in relation to the Danish mandatory pediatric examination program (yearly screens for development and thriving) and the national vaccination program were not considered. We also obtained information on contacts to private practicing doctors other than GPs. Finally, we obtained information on consultations with GPs on call. From the NPR, we collected information on all contacts to elective outpatient departments, in-patient hospitalizations and to emergency departments. We created the variable 'all contacts' which included all primary and secondary health care contacts for the time windows 0-24 months, 19-24 months, 13-18 months, 7-12 months, 4-6 months and 0-3 months prior to diagnosis, and respectively for 'emergency contacts' that included all GP on call contacts, emergency room contacts and acute hospitalizations for the equivalent time windows. Based on the distribution of health care contacts throughout the full period of 24 months prior to diagnosis, we defined the period of primary interest as the period immediately up to diagnosis. Due to a similar pattern across all diagnostic groups, this was defined as the last 3 months prior to diagnosis. For this period, we classified contacts into frequent and less frequent based on the median number of contacts for all contacts and emergency contacts.

\section{Stage}

We defined stage individually by cancer type based on clinical considerations, as different cancer types are biologically very heterogeneous. The availability of appropriate clinical information was limited to certain cancer types and included B-cell acute lymphoblastic leukemia (ALL), T- cell ALL, Hodgkin lymphoma, non-Hodgkin and Burkitt lymphoma, Ewing's sarcoma, osteosarcoma and rhabdomyosarcoma. Based on data availability, we used either the Toronto Pediatric Cancer Staging criteria [43] or similar measure as available from the DCCR. For ALL, we categorized white blood cell count at diagnosis $(\mathrm{WBC})<100 \times 10^{9} / \mathrm{L}$ as low stage and $\mathrm{WBC} \geq 100 \times 10^{9} /$ $\mathrm{L}$ as advanced stage. For lymphoma, we categorized stage $1-2$ as low stage and stage $3-4$ as advanced stage. For the groups of bone tumors and soft tissue sarcomas, 
we categorized stage as no distant metastases/unknown as low stage and distant metastases as advanced stage.

\section{Statistical analyses}

Descriptive analyses were performed to describe the number of children diagnosed with cancer at ages 0-15 years in total and by highest parental education in the household. To investigate the number of contacts in the 24 months prior to diagnosis, we plotted the number of contacts by time before diagnosis for each of the defined diagnostic groups.

Logistic regression was used to estimate multivariateadjusted odds ratios (OR) and 95\% confidence intervals (CI) for the association between selected socioeconomic variables and the odds of frequent contacts to the health care system in the last 3 months before diagnosis for all contacts and emergency contacts respectively. Two models were used. In the first model we adjusted for diagnostic group, sex, period of diagnosis and age at diagnosis (as a continuous variable), and in the second model, we additionally adjusted for highest parental education in household and household cohabitation status. We analyzed each SEP variable separately, however, adjusted for education and cohabitation status as we understand them as potential confounders on the association between other SEP indicators and health care use. To assess effect modification, we conducted stratified analyses by diagnostic groups, sex and age at diagnosis $(0,1-4,5-10,11-15)$, including the variable in question as an interaction term.

Finally, we considered the association between highest parental education in the household, household cohabitation status and depression in household parents and disease stage in a subpopulation. Logistic regression was used to estimate multivariate-adjusted ORs and 95\% CI for the association between the selected socioeconomic variables and the odds of advanced stage. Again, two models were used. In the first model we adjusted for sex, period of diagnosis and age at diagnosis (as a continuous variable), highest parental education in the household and household cohabitation, and in the second model we additionally adjusted for total number of contacts in the 24 months before diagnosis (as a continuous variable). In both models diagnostic subgroup was included as an interaction term.

Statistical significance was considered at a 5\% level, and all statistical analyses were conducted using the statistical software $R$, version 3.6.3.

\section{Results}

\section{Study population}

From our initial sample of 3115 children, we excluded 26 children who were living in own households or with no adults and 18 with missing information on affiliation to work market and/or income. Furthermore, we excluded 28 children diagnosed on their date of birth, resulting in a final study population of 3043 children diagnosed with cancer. The most common diagnoses included leukemia (30\%) and CNS tumors (27\%). Almost half of the children were diagnosed before the age of 5 years $(45 \%)$ (Table 1 ). About $45 \%$ of the children were living in families with long and $12 \%$ with short parental education. Compared to families with medium or long parental education, families with short parental education were more often young (mothers $\leq 30$ years, 38\%), had low income $(14 \%$ Q1 and $28 \%$ Q2), were unemployed (42\%), were single parents (46\%), originated from a non-Western country (26\%), and had a depression (19\%) compared to families with medium or long parental education.

\section{Contacts with the health care system}

Among all childhood cancer patients, children diagnosed with leukemia had the highest number of all contacts (all primary and secondary health care contacts) and emergency contacts (all GP on call contacts, emergency room contacts and acute hospitalizations) to the health care system throughout the 24 months as well as in the 3 months before diagnosis (Supplementary Table 1).

Number of contacts were particular high during the last 3 months prior to diagnosis across all diagnostic groups. For this period, $47 \%$ of the 3043 children showed frequent contacts ( $\geq 8$ contacts) to the health care system and $43 \%$ had frequent emergency contacts ( $\geq 2$ emergency contacts). Figure 1 shows the median number of contacts by time before diagnosis and by parental education for the diagnostic groups.

While there is no clear pattern by education over time from 24 to 4 months before diagnosis across diagnostic groups, there is an indication that children living in families with short parental education and diagnosed with leukemia, lymphoma or CNS tumors had more contacts in the last 3 months prior to diagnosis than children from families with medium or long parental education. Similar plots for household cohabitation status indicated no differences in number of contacts over the 24 months prior to diagnosis (data not shown).

\section{Frequent contacts with the health care system}

Analyzing specifically the last 3 months prior to diagnosis, children from families with short parental education had higher ORs of frequent contacts to the health care system across diagnostic groups compared to families with long education (Table 2), although only statistically significant for CNS tumors (OR: 1.81; 95\% CI: $1.12-$ 2.93). Similarly increased ORs of frequent contacts across diagnostic groups were observed in children from 
Table 1 Characteristics of the study population by highest parental education in the household

\begin{tabular}{|c|c|c|c|c|}
\hline \multirow[t]{3}{*}{ Characteristics } & \multicolumn{3}{|c|}{ Highest parental education in the household ${ }^{a}$} & \multirow{3}{*}{$\begin{array}{l}\text { Total } \\
\text { N (\%) }\end{array}$} \\
\hline & Short & Medium & Long & \\
\hline & $\mathrm{N}(\%)$ & $\mathrm{N}(\%)$ & $\mathrm{N}(\%)$ & \\
\hline No. of patients (1998-2016) & $354(100)$ & $1316(100)$ & $1373(100)$ & $3043(100)$ \\
\hline \multicolumn{5}{|l|}{ Age at diagnosis (years) } \\
\hline 0 & $41(12)$ & $132(10)$ & $131(10)$ & $304(10)$ \\
\hline $1-4$ & $123(35)$ & $417(32)$ & $534(39)$ & $1074(35)$ \\
\hline $5-10$ & $113(32)$ & $390(30)$ & $394(29)$ & $897(29)$ \\
\hline $11-15$ & $77(22)$ & $377(29)$ & $314(23)$ & $768(25)$ \\
\hline \multicolumn{5}{|l|}{ Sex } \\
\hline Female & $151(43)$ & $599(46)$ & $672(49)$ & $1422(47)$ \\
\hline Male & $203(57)$ & $717(54)$ & $701(51)$ & $1621(53)$ \\
\hline \multicolumn{5}{|l|}{ Period of diagnosis } \\
\hline 1998-2001 & $81(23)$ & $350(27)$ & $245(18)$ & $676(22)$ \\
\hline $2002-2006$ & $98(28)$ & $368(28)$ & $332(24)$ & $798(26)$ \\
\hline $2007-2011$ & $90(25)$ & $326(25)$ & $387(28)$ & $803(26)$ \\
\hline $2012-2016$ & $85(24)$ & $272(21)$ & $409(30)$ & $766(25)$ \\
\hline \multicolumn{5}{|l|}{ Diagnostic group } \\
\hline Leukemia & $103(29)$ & $382(29)$ & $420(31)$ & $905(30)$ \\
\hline Lymphoma & $43(12)$ & $135(10)$ & $136(10)$ & $314(10)$ \\
\hline CNS tumors & $88(25)$ & $362(28)$ & $355(26)$ & $805(26)$ \\
\hline Bone tumors and soft tissue sarcomas & $39(11)$ & $139(11)$ & $143(10)$ & $321(11)$ \\
\hline Other non-CNS solid tumors & $81(23)$ & $298(23)$ & $319(23)$ & $698(23)$ \\
\hline \multicolumn{5}{|l|}{ Age of mother at time of diagnosis } \\
\hline$\leq 25$ & $59(17)$ & $70(5)$ & $12(1)$ & $141(5)$ \\
\hline $26-30$ & $75(21)$ & $204(16)$ & $157(11)$ & $436(14)$ \\
\hline $31-35$ & $93(26)$ & $340(26)$ & $387(28)$ & $820(27)$ \\
\hline $36-40$ & $70(20)$ & $356(27)$ & $428(31)$ & $854(28)$ \\
\hline$\geq 41$ & $46(13)$ & $325(25)$ & $372(27)$ & $743(24)$ \\
\hline Household without mother & $11(3)$ & $21(2)$ & $17(1)$ & $49(2)$ \\
\hline \multicolumn{5}{|l|}{ Age of father at time of diagnosis } \\
\hline$\leq 30$ & $51(14)$ & $172(13)$ & $90(7)$ & $313(10)$ \\
\hline $31-35$ & $45(13)$ & $250(19)$ & $300(22)$ & $595(20)$ \\
\hline $36-40$ & $48(14)$ & $282(21)$ & $378(28)$ & $708(23)$ \\
\hline$\geq 41$ & $60(17)$ & $437(33)$ & $516(38)$ & $1013(33)$ \\
\hline Household without father & $150(42)$ & $175(13)$ & $89(6)$ & $414(14)$ \\
\hline \multicolumn{5}{|l|}{ Household cohabitation status } \\
\hline Living as a couple (with unknown relation) & $193(55)$ & $1120(85)$ & $1267(92)$ & $2580(85)$ \\
\hline Living alone (single parent) & $161(45)$ & $196(15)$ & $106(8)$ & $463(15)$ \\
\hline \multicolumn{5}{|l|}{ Highest parental income in household ${ }^{b}$} \\
\hline Fifth quintile & $70(20)$ & $275(21)$ & $579(42)$ & $924(30)$ \\
\hline Fourth quintile & $56(16)$ & $365(28)$ & $440(32)$ & $861(28)$ \\
\hline Third quintile & $79(22)$ & $357(27)$ & $221(16)$ & $657(22)$ \\
\hline Second quintile & $98(28)$ & $231(18)$ & $103(8)$ & $432(14)$ \\
\hline First quintile & $51(14)$ & $88(7)$ & $30(2)$ & $169(6)$ \\
\hline
\end{tabular}


Table 1 Characteristics of the study population by highest parental education in the household (Continued)

\begin{tabular}{|c|c|c|c|c|}
\hline \multirow[t]{3}{*}{ Characteristics } & \multicolumn{3}{|c|}{ Highest parental education in the household ${ }^{a}$} & \multirow{3}{*}{$\begin{array}{l}\text { Total } \\
\text { N (\%) }\end{array}$} \\
\hline & Short & Medium & Long & \\
\hline & $\mathrm{N}(\%)$ & $\mathrm{N}(\%)$ & $\mathrm{N}(\%)$ & \\
\hline \multicolumn{5}{|c|}{ Household affiliation to work market $^{c}$} \\
\hline At work & $133(38)$ & $947(72)$ & $1162(85)$ & $2242(74)$ \\
\hline Mixed & $74(21)$ & $266(20)$ & $164(12)$ & $504(17)$ \\
\hline Unemployed/not in work force & $147(42)$ & $103(8)$ & $47(3)$ & $297(10)$ \\
\hline \multicolumn{5}{|c|}{ Country of origin for household parent(s) ${ }^{d}$} \\
\hline Denmark & $243(68)$ & $1131(86)$ & $1213(88)$ & $2586(85)$ \\
\hline Western countries & $9(3)$ & $14(1)$ & $20(1)$ & $43(1)$ \\
\hline Non-Western countries & $93(26)$ & $133(10)$ & $69(5)$ & $295(10)$ \\
\hline Mixed & $10(3)$ & $38(3)$ & $71(5)$ & $119(4)$ \\
\hline \multicolumn{5}{|l|}{ Number of children in household } \\
\hline 1 & $94(27)$ & $326(25)$ & $291(21)$ & $711(23)$ \\
\hline 2 & $145(41)$ & $625(47)$ & $708(52)$ & $1478(49)$ \\
\hline$\geq 3$ & $115(32)$ & $365(28)$ & $374(27)$ & $854(28)$ \\
\hline \multicolumn{5}{|l|}{ Depression in household parent(s) } \\
\hline No & $288(81)$ & $1132(86)$ & $1248(91)$ & $2668(88)$ \\
\hline Yes & $66(19)$ & $184(14)$ & $125(9)$ & $375(12)$ \\
\hline \multicolumn{5}{|c|}{ Somatic or major psychiatric disease in household parent(s) } \\
\hline None & $310(88)$ & $1182(90)$ & $1247(91)$ & $2739(90)$ \\
\hline One or more & $44(12)$ & $134(10)$ & $126(9)$ & $304(10)$ \\
\hline
\end{tabular}

${ }^{a}$ Highest parental education in the household categorized into short $(<10$ years, primary and lower secondary education), medium (10-12 years, upper secondary and vocational education) and higher education ( $\geq 3$ years, higher education)

${ }^{b}$ Highest parental income in household categorized into quintiles with first quintile as the lowest $(<20 \%)$. This is based on the highest annual disposable parental income in household based on the income quintile of the entire Danish population by birth cohort, calendar year and sex

'Household affiliation to work market categorized into at work, unemployed/not in work force and mixed (one household parent at work and one unemployed/ not in work force)

${ }^{\mathrm{d} C o u n t r y}$ of origin of household parents categorized into Denmark, Western country, Non-western country and mixed (household parents belong to different country categories)

families with mixed affiliation to the work market compared to working parents, reaching statistical significance for leukemia (OR: 1.80; 95\% CI: 1.22-2.66) as well as for other non-CNS solid tumors (OR: 1.97; 95\% CI: 1.34-2.91). Lower ORs were seen for children of single parents for all diagnostic groups with the exception of bone tumors and soft tissue sarcomas; however, none of them reached statistical significance. Depression in household parents was (with the exception of children with lymphoma) associated with elevated ORs for frequent contacts, reaching statistical significance in children with CNS tumors (OR: 1.56; 95\% CI: 1.04-2.34). We found no clear pattern of associations with income, number of children in household and somatic and major psychiatric disease in parents.

For emergency contacts (Table 3), we similarly observed higher OR of frequent emergency contacts among children from families with short parental education compared to households with long education across most diagnostic groups, however, only statistically significant for lymphoma (OR: 2.59; 95\% CI: 1.27-5.29).
ORs for most diagnostic groups were also higher among children from families with mixed affiliation to work market and with parents of non-Western origin, although confidence intervals were in general wide. A distinct association between depression in household parents and frequent emergency contacts was found among children with CNS tumors (OR: 2.13; 95\% CI: 1.41-3.23), while ORs for children from households with parental somatic or major psychiatric disease were increased for leukemia and CNS tumors, albeit not statistically significant. Conversely, somatic or major psychiatric disease was associated with an OR of 0.36 (95\% CI: 0.14; 0.98) among children with bone tumors and soft tissue sarcomas. No obvious pattern in ORs was noted for cohabitation status, income and number of children in household.

Stratified analysis of the total sample by sex and age group revealed that increased OR of frequent contacts for children in families with short parental education compared to long education was more pronounced among boys (OR: 1.68; 95\% CI: 1.20-2.34) than girls 

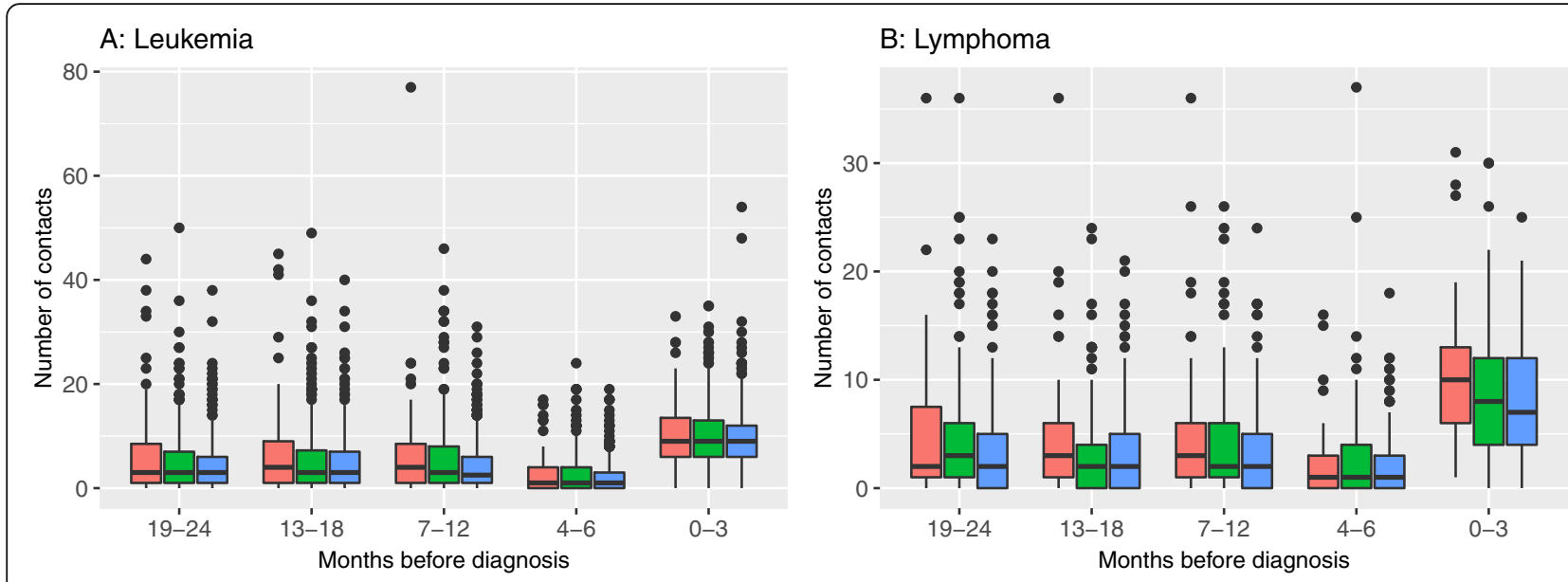

\section{C: CNS tumors}
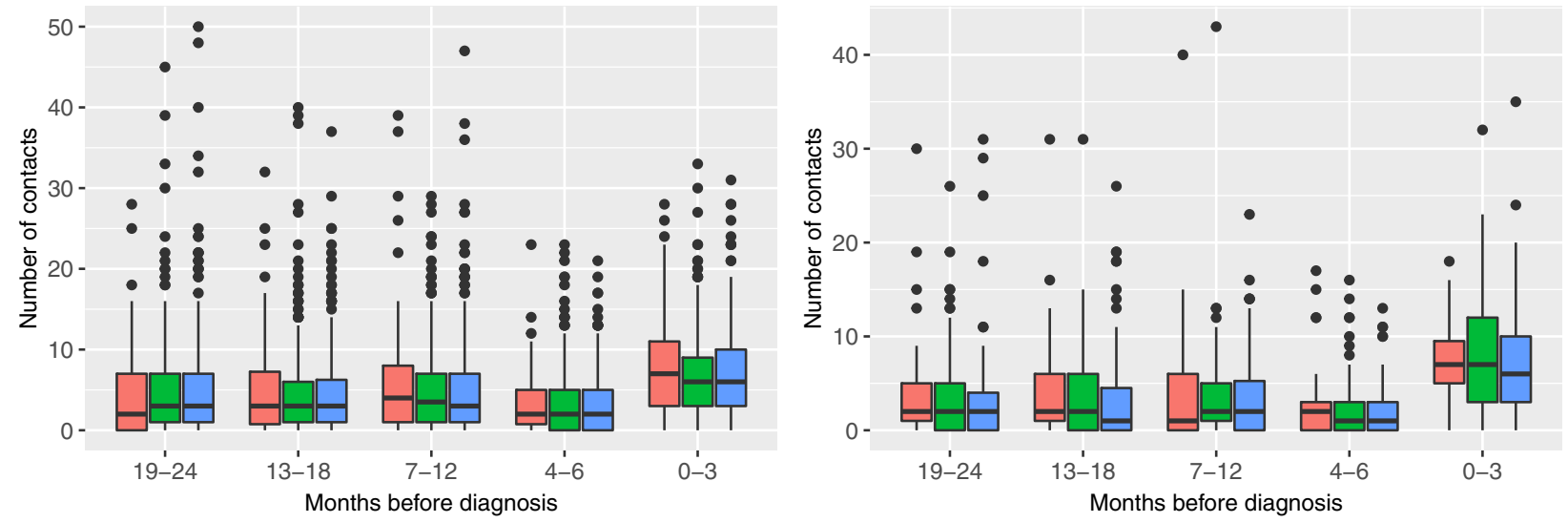

E: Other non-CNS solid tumors

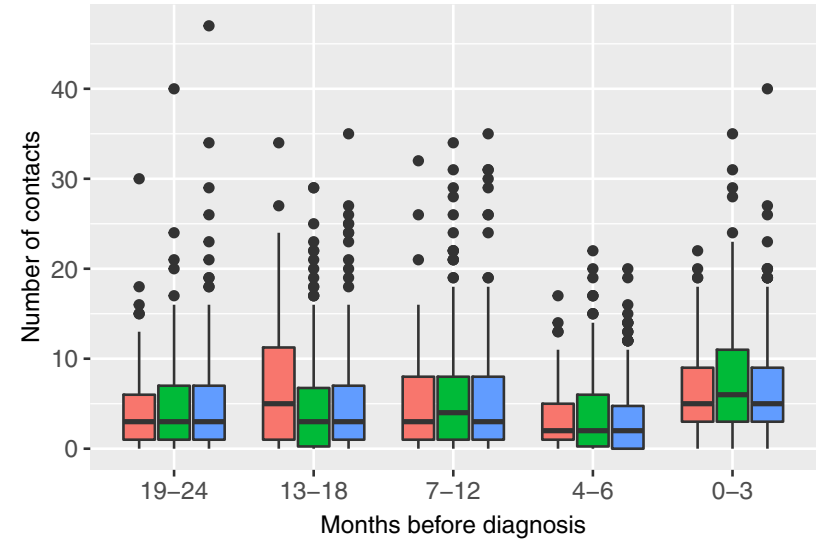

Highest parental education in the household追 Short 官 Medium 官 Long

Fig. 1 Distribution of pre-diagnostic contacts to the health care system in children diagnosed with cancer 0-24 months before diagnosis by highest parental education in the household, diagnostic group and time since diagnosis. The length of the box represents the interquartile range, the horizontal black line in the box interior represents the median, and the dots represent outliers

(OR: 1.12; 95\% CI: 0.77-1.63), while the association of depression in household parent with OR of frequent emergency contacts seemed stronger among girls (OR: 1.60; 95\% CI: $1.14-2.25$ ) than among boys (OR: 1.09 ;
95\% CI: 0.80-1.49) (data not shown). In general, the ORs were higher among children from families with mixed affiliation to work market compared to working parents across age groups, however, reaching statistical 
Table 2 Odds ratio $(95 \% \mathrm{Cl})$ of frequent contacts to the health care system (all contacts)

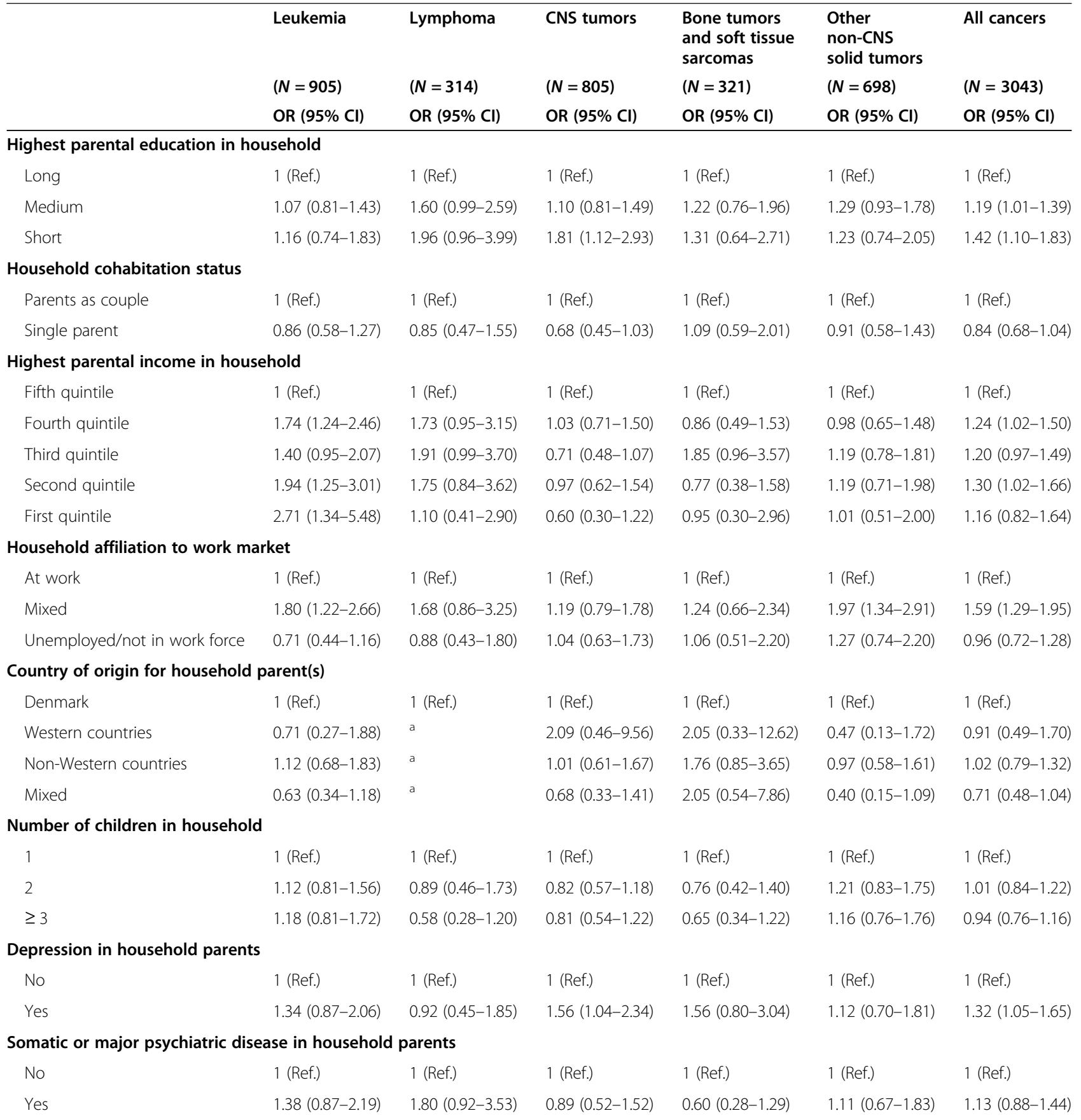

Frequent contacts are defined as 8 or more contacts to doctors in primary care sector, emergency room contacts, outpatient and inpatient hospital contacts during the last 3 months before child's cancer diagnosis; OR Odds Ratio, Cl confidence interval. For each socioeconomic variable, the models are adjusted for sex, diagnostic group (as an interaction term in the model, where we estimate the OR for each diagnostic group), diagnosis period and age at diagnosis (continuous), highest parental education in the household and household cohabitation status. ${ }^{a}$ Due to few observations, logistic regression analysis did not reach convergence.

significance only in infants (OR: $2.32,95 \% \mathrm{CI}: 1.31-4.10)$ and the youngest children (OR: $1.77,95 \%$ CI: $1.29-2.44$ ) (data not shown).

\section{Stage of disease}

The sample for analyses of stage in selected cancer types included a total of 1074 children (Table 4). There was no clear pattern of an association between highest education in household parents, household cohabitation status or depression in household parent with advanced stage for the selected cancer types except for B-cell ALL, where the OR of advanced stage was increased among children of single parent households (OR: 2.39; 95\% CI: 1.14-4.99) compared to cohabiting parents (Table 4). Adjusting for number of 
health care contacts did not change the estimates considerably (Table 4), nor did excluding age from the models.

\section{Discussion}

In this unique nationwide register-based study with minimal risk of bias, there seems to be an association between several indicators of family SEP, parental health and prediagnostic health care contacts among children diagnosed with cancer in Denmark. Children from households with short parental education, mixed affiliation to the work market or a parent with depression had a higher likelihood of frequent contacts overall in the last 3 months before diagnosis when compared to children with parents who have long education, are working and are not treated for depression. Further, our analyses indicate increased use of emergency health care among families with short education, mixed affiliation to work market and non-Western origin in the last 3 months before diagnosis and point towards possible differences in utilization and understanding of the health care system by socioeconomic group in Denmark. Reassuringly, we found no convincing evidence for an association between SEP and stage at diagnosis and our findings do not indicate that children of lower SEP are of higher risk of more advanced disease at diagnosis.

Socioeconomic differences in the number of prediagnostic health care contacts were also found in an earlier Danish population-based study, which showed that children with cancer had more contacts than their cancerfree peers and further that children with cancer from low- and medium-income families had higher odds of frequent contacts to their GP compared to high-income families the last 3 months prior to diagnosis [19]. Taking together, these observations and our findings point towards possible differences in understanding of the health care system by SEP. The knowledge and skills attained through e.g. education may help parents in decisions about care seeking, and to communicate, negotiate and access appropriate health services [37]. An increased contact frequency among families with low SEP may thus be due to socioeconomic differences in health literacy and/or a social gradient in the communication between families and health care professionals [44, 45]. Indeed research has shown that SEP of the parents may influence the clinicians' approach; how they involve the parents in the clinical setting [16], and which themes are addressed in the consultation [45]. The doctor-patient/ parent relationship in the prediagnostic period of childhood cancer has been explored in qualitative studies [13, 16, 45-47] including parents with different level of SEP describing differences in proactive and strategic roles in the process of obtaining a diagnosis [13, 46, 47]. A recent Danish interview study $(N=46)$ described this as a mechanism where some parents take advantage of their health-relevant cultural capital [48] in the process of obtaining a diagnosis. The strategic approach enabled them to negotiate with their GP, e.g. about further diagnostic tests and thereby speeding up the process of obtaining a diagnosis [47]. As health-relevant cultural capital is related to the SEP [48] of individuals, this mechanism may contribute to explaining our findings that children with parents of short education, looser affiliation to the work market and with depression have a higher risk of frequent contacts prior to diagnosis.

We observed no differential contact pattern by SEP in the (probably) pre-symptomatic period where number of contacts were similar and stable across SEP groups up to about 3 months prior to diagnosis at cancer group level. A pattern of more frequent contacts and likely less optimal diagnostic trajectories among groups of low SEP have been seen in general outside the cancer setting among children of parents with short education [49], children of immigrant parents $[49,50]$ and children with parental depression [51], while our results indicate that disparities may be confined to the presumed symptomatic period leading to diagnosis. Despite an association between childhood cancer and alert symptoms presented in general practice [52], a registry study from the UK [52], as well as a questionnaire study among Danish GPs $(n=363)$ [53], found alert symptoms to be relatively uncommon among these children. With few cases yearly, neither the GP, the GP on call nor health care professionals at the emergency departments may encounter a case of childhood cancer throughout their career. Likewise, parents most commonly have no experience with the symptoms of childhood cancer.

A significant strength of our study is the use of reliable population-based register data with almost complete coverage, not influenced by self-reports or nonparticipation which enables epidemiological research of high validity [54]. The complete registration independent of study hypothesis enabled us to include virtually all children diagnosed with cancer in 1998-2016 in Denmark with only few exclusions and thus minimal risk for selection bias. Annual information on SEP indicators minimized the risk of information bias often noted in self-reported data and provided us with comprehensive socioeconomic information. The inclusion of prediagnostic contacts of both primary and secondary care in our study and an explicit focus on the acute setting supports and extends the knowledge about health care use and socioeconomic disparities before diagnosis of childhood cancer.

Another strength of our study concerns the possibility to measure SEP on a household basis and not the one-sided view of the socioeconomic resources of either parent. We did not differentiate between 
Table 3 Odds ratio $(95 \% \mathrm{Cl})$ of frequent emergency contacts to the health care system

\begin{tabular}{|c|c|c|c|c|c|c|}
\hline & Leukemia & Lymphoma & CNS tumors & $\begin{array}{l}\text { Bone tumors } \\
\text { and soft tissue } \\
\text { sarcomas }\end{array}$ & $\begin{array}{l}\text { Other non-CNS } \\
\text { solid tumors }\end{array}$ & All cancers \\
\hline & $(N=905)$ & $(N=314)$ & $(N=805)$ & $(N=321)$ & $(N=698)$ & $(N=3043)$ \\
\hline & OR (95\% Cl) & OR $(95 \% \mathrm{Cl})$ & OR $(95 \% \mathrm{CI})$ & OR $(95 \% \mathrm{CI})$ & OR (95\% CI) & OR $(95 \% \mathrm{Cl})$ \\
\hline \multicolumn{7}{|c|}{ Highest parental education in household } \\
\hline Long & 1 (Ref.) & 1 (Ref.) & 1 (Ref.) & 1 (Ref.) & 1 (Ref.) & 1 (Ref.) \\
\hline Medium & $1.02(0.76-1.37)$ & $0.98(0.59-1.61)$ & $1.22(0.89-1.68)$ & $0.81(0.48-1.36)$ & $0.98(0.70-1.38)$ & $1.03(0.87-1.21)$ \\
\hline Short & $1.03(0.64-1.64)$ & $2.59(1.27-5.29)$ & $1.62(0.99-2.66)$ & $1.31(0.61-2.79)$ & $1.19(0.72-1.99)$ & $1.39(1.07-1.80)$ \\
\hline \multicolumn{7}{|l|}{ Household cohabitation status } \\
\hline Parents as couple & 1 (Ref.) & 1 (Ref.) & 1 (Ref.) & 1 (Ref.) & 1 (Ref.) & 1 (Ref.) \\
\hline Single parent & $0.88(0.59-1.32)$ & $0.95(0.51-1.74)$ & $1.02(0.68-1.53)$ & $1.89(1.00-3.57)$ & $0.94(0.59-1.49)$ & $1.02(0.81-1.27)$ \\
\hline \multicolumn{7}{|c|}{ Highest parental income in household } \\
\hline Fifth quintile & 1 (Ref.) & 1 (Ref.) & 1 (Ref.) & 1 (Ref.) & 1 (Ref.) & 1 (Ref.) \\
\hline Fourth quintile & $1.14(0.80-1.63)$ & $1.12(0.60-2.10)$ & $1.21(0.81-1.79)$ & $1.07(0.58-1.97)$ & $0.88(0.58-1.34)$ & $1.08(0.88-1.31)$ \\
\hline Third quintile & $0.90(0.60-1.34)$ & $1.55(0.79-3.04)$ & $1.10(0.72-1.66)$ & $0.81(0.39-1.68)$ & $1.00(0.66-1.54)$ & $1.03(0.82-1.28)$ \\
\hline Second quintile & $0.79(0.51-1.23)$ & $1.28(0.61-2.70)$ & $1.13(0.70-1.82)$ & $0.87(0.40-1.90)$ & $0.74(0.43-1.26)$ & $0.91(0.70-1.17)$ \\
\hline First quintile & $1.22(0.61-2.44)$ & $1.58(0.59-4.23)$ & $0.79(0.38-1.65)$ & $1.19(0.36-3.92)$ & $0.97(0.49-1.94)$ & $1.06(0.74-1.51)$ \\
\hline \multicolumn{7}{|c|}{ Household affiliation to work market } \\
\hline At work & 1 (Ref.) & 1 (Ref.) & 1 (Ref.) & 1 (Ref.) & 1 (Ref.) & 1 (Ref.) \\
\hline Mixed & $1.31(0.89-1.93)$ & $0.88(0.45-1.72)$ & $1.08(0.71-1.64)$ & $1.60(0.82-3.11)$ & $1.48(1.00-2.20)$ & $1.26(1.02-1.56)$ \\
\hline Unemployed/not in work force & $0.86(0.52-1.43)$ & $1.32(0.64-2.72)$ & $0.91(0.53-1.54)$ & $1.80(0.85-3.81)$ & $1.09(0.62-1.91)$ & $1.06(0.79-1.42)$ \\
\hline \multicolumn{7}{|c|}{ Country of origin for household parent(s) } \\
\hline Denmark & 1 (Ref.) & 1 (Ref.) & 1 (Ref.) & 1 (Ref.) & 1 (Ref.) & 1 (Ref.) \\
\hline Western countries & $1.53(0.49-4.79)$ & a & $11.50(1.35-97.64)$ & $1.62(0.26-10.03)$ & $0.86(0.26-2.85)$ & $1.82(0.94-3.50)$ \\
\hline Non-Western countries & $1.37(0.80-2.32)$ & a & $1.05(0.63-1.75)$ & $2.07(0.99-4.33)$ & $2.10(1.27-3.49)$ & $1.49(1.15-1.94)$ \\
\hline Mixed & $0.66(0.35-1.26)$ & a & $0.56(0.25-1.25)$ & $3.65(0.95-14.04)$ & $1.71(0.75-3.88)$ & $0.93(0.62-1.38)$ \\
\hline \multicolumn{7}{|l|}{ Number of children in household } \\
\hline 1 & 1 (Ref.) & 1 (Ref.) & 1 (Ref.) & 1 (Ref.) & 1 (Ref.) & 1 (Ref.) \\
\hline 2 & $0.83(0.58-1.17)$ & $0.76(0.39-1.47)$ & $1.15(0.79-1.68)$ & $0.63(0.33-1.19)$ & $0.95(0.65-1.40)$ & $0.93(0.76-1.13)$ \\
\hline$\geq 3$ & $0.93(0.62-1.38)$ & $0.63(0.30-1.33)$ & $0.59(0.38-0.92)$ & $0.68(0.35-1.32)$ & $1.74(1.14-2.65)$ & $0.92(0.74-1.14)$ \\
\hline \multicolumn{7}{|l|}{ Depression in household parents } \\
\hline No & 1 (Ref.) & 1 (Ref.) & 1 (Ref.) & 1 (Ref.) & 1 (Ref.) & 1 (Ref.) \\
\hline Yes & $1.02(0.66-1.57)$ & $1.08(0.53-2.22)$ & $2.13(1.41-3.23)$ & $1.29(0.63-2.61)$ & $0.97(0.59-1.59)$ & $1.30(1.03-1.64)$ \\
\hline \multicolumn{7}{|c|}{ Somatic or major psychiatric disease in household parents } \\
\hline No & 1 (Ref.) & 1 (Ref.) & 1 (Ref.) & 1 (Ref.) & 1 (Ref.) & 1 (Ref.) \\
\hline Yes & $1.28(0.80-2.06)$ & $0.97(0.50-1.90)$ & $1.43(0.84-2.42)$ & $0.36(0.14-0.98)$ & $1.00(0.59-1.69)$ & $1.07(0.83-1.37)$ \\
\hline
\end{tabular}

Frequent contacts are defined as 2 or more contacts to GPs on call in primary care sector and emergency room contacts during the last 3 months before child's cancer diagnosis; OR Odds Ratio, Cl confidence interval. For each socioeconomic variable, the models are adjusted for sex, diagnostic group (as an interaction term in the model, where we estimate the OR for each diagnostic group), diagnosis period and age at diagnosis (continuous), highest parental education in the household and household cohabitation status. ${ }^{a}$ Due to few observations, logistic regression analysis did not reach convergence.

whether the child was living with the father or the mother if living with a single parent. As according to Danish law, inhabitants, including children, can only be registered at one address although separated parents commonly share child custody in Denmark and children may live at two households, we were only able to capture the household information the child was registered at and we applied the socioeconomic and health information of the household parents based on the assumption that this represents the family circumstances of the child. Anyhow, in Denmark, all health care services for children are free in both the primary and secondary health care system and the parent's social or health resources should formally not 
Table 4 Odds ratio $(95 \% \mathrm{Cl})$ of advanced stage of disease at diagnosis in 1074 children

\begin{tabular}{|c|c|c|c|c|}
\hline & Advanced stage & Low stage & Model $1^{\text {a }}$ & Model $2^{b}$ \\
\hline \multicolumn{5}{|c|}{ B-cell acute lymphoblastic leukemiac $(N=601)$} \\
\hline \multicolumn{5}{|c|}{ Highest parental education in household } \\
\hline Long & 20 & 270 & 1 (Ref.) & 1 (Ref.) \\
\hline Medium & 18 & 233 & $1.07(0.55-2.08)$ & $1.09(0.56-2.13)$ \\
\hline Short & 5 & 55 & $1.01(0.35-2.92)$ & $1.07(0.37-3.08)$ \\
\hline \multicolumn{5}{|c|}{ Household cohabitation status } \\
\hline Parents as couple & 31 & 480 & 1 (Ref.) & 1 (Ref.) \\
\hline Single parent & 12 & 78 & $2.39(1.14-4.99)$ & $2.36(1.13-4.95)$ \\
\hline \multicolumn{5}{|c|}{ Depression in household parents } \\
\hline No & NA & 503 & 1 (Ref.) & 1 (Ref.) \\
\hline Yes & NA & 55 & $0.64(0.19-2.15)$ & $0.68(0.20-2.30)$ \\
\hline \multicolumn{5}{|c|}{ T-cell acute lymphoblastic leukemia ${ }^{c}(N=98)$} \\
\hline \multicolumn{5}{|c|}{ Highest parental education in household } \\
\hline Long & 19 & 21 & 1 (Ref.) & 1 (Ref.) \\
\hline Medium & 20 & 27 & $0.83(0.35-1.96)$ & $0.84(0.35-1.98)$ \\
\hline Short & 5 & 6 & $0.86(0.22-3.35)$ & $0.92(0.24-3.60)$ \\
\hline \multicolumn{5}{|c|}{ Household cohabitation status } \\
\hline Parents as couple & 38 & 46 & 1 (Ref.) & 1 (Ref.) \\
\hline Single parent & 6 & 8 & $0.99(0.31-3.19)$ & $0.98(0.30-3.18)$ \\
\hline \multicolumn{5}{|c|}{ Depression in household parents } \\
\hline No & 37 & 44 & & 1 (Ref.) \\
\hline Yes & 7 & 10 & $0.89(0.30-2.62)$ & $0.85(0.29-2.51)$ \\
\hline \multicolumn{5}{|c|}{ Hodgkin lymphoma $^{d}(N=89)$} \\
\hline \multicolumn{5}{|c|}{ Highest parental education in household } \\
\hline Long & NA & 30 & 1 (Ref.) & 1 (Ref.) \\
\hline Medium & NA & 24 & $1.42(0.57-3.53)$ & $1.60(0.63-4.03)$ \\
\hline Short & NA & 4 & $0.45(0.04-4.46)$ & $0.52(0.05-5.21)$ \\
\hline \multicolumn{5}{|c|}{ Household cohabitation status } \\
\hline Parents as couple & 26 & 49 & 1 (Ref.) & 1 (Ref.) \\
\hline Single parent & 5 & 9 & $1.17(0.35-3.93)$ & $1.13(0.34-3.78)$ \\
\hline \multicolumn{5}{|c|}{ Depression in household parents } \\
\hline No & 26 & 53 & 1 (Ref.) & 1 (Ref.) \\
\hline Yes & 5 & 5 & $1.80(0.46-7.00)$ & $1.98(0.50-7.78)$ \\
\hline \multicolumn{5}{|c|}{ Non-Hodgkin and Burkitt lymphoma ${ }^{d}(N=98)$} \\
\hline \multicolumn{5}{|c|}{ Highest parental education in household } \\
\hline Long & 34 & NA & 1 (Ref.) & 1 (Ref.) \\
\hline Medium & 20 & NA & $0.32(0.13-0.81)$ & $0.34(0.13-0.85)$ \\
\hline Short & 11 & NA & $3.82(0.44-33.29)$ & $3.95(0.45-34.50)$ \\
\hline \multicolumn{5}{|c|}{ Household cohabitation status } \\
\hline Parents as couple & 53 & 26 & 1 (Ref.) & 1 (Ref.) \\
\hline Single parent & 12 & 7 & $0.85(0.29-2.45)$ & $0.86(0.30-2.48)$ \\
\hline \multicolumn{5}{|c|}{ Depression in household parents } \\
\hline No & 57 & 27 & 1 (Ref.) & 1 (Ref.) \\
\hline Yes & 8 & 6 & $0.66(0.20-2.12)$ & $0.64(0.20-2.08)$ \\
\hline
\end{tabular}


Table 4 Odds ratio $(95 \% \mathrm{Cl})$ of advanced stage of disease at diagnosis in 1074 children (Continued)

\begin{tabular}{|c|c|c|c|c|}
\hline & Advanced stage & Low stage & Model $1^{a}$ & Model $2^{b}$ \\
\hline \multicolumn{5}{|c|}{ Ewing's sarcoma $^{\mathrm{e}}(N=86)$} \\
\hline \multicolumn{5}{|c|}{ Highest parental education in household } \\
\hline Long & NA & 30 & 1 (Ref.) & 1 (Ref.) \\
\hline Medium & NA & 23 & $1.86(0.68-5.08)$ & $1.91(0.70-5.24)$ \\
\hline Short & NA & 9 & $0.27(0.03-2.48)$ & $0.28(0.03-2.57)$ \\
\hline \multicolumn{5}{|c|}{ Household cohabitation status } \\
\hline Parents as couple & 20 & 50 & 1 (Ref.) & 1 (Ref.) \\
\hline Single parent & 4 & 12 & $0.76(0.21-2.71)$ & $0.75(0.21-2.68)$ \\
\hline \multicolumn{5}{|c|}{ Depression in household parents } \\
\hline No & 20 & 53 & 1 (Ref.) & 1 (Ref.) \\
\hline Yes & 4 & 9 & $1.15(0.31-4.28)$ & $1.26(0.34-4.75)$ \\
\hline \multicolumn{5}{|l|}{ Osteosarcoma $^{\mathrm{e}}(N=62)$} \\
\hline \multicolumn{5}{|c|}{ Highest parental education in household } \\
\hline Long & NA & 19 & 1 (Ref.) & 1 (Ref.) \\
\hline Medium & NA & 22 & $1.66(0.43-6.49)$ & $1.68(0.43-6.57)$ \\
\hline Short & NA & 6 & $2.25(0.37-13.58)$ & $2.36(0.39-14.32)$ \\
\hline \multicolumn{5}{|c|}{ Household cohabitation status } \\
\hline Parents as couple & 11 & 39 & 1 (Ref.) & 1 (Ref.) \\
\hline Single parent & 4 & 8 & $1.86(0.46-7.53)$ & $1.86(0.46-7.58)$ \\
\hline \multicolumn{5}{|c|}{ Depression in household parents } \\
\hline No & NA & 38 & 1 (Ref.) & 1 (Ref.) \\
\hline Yes & NA & 9 & $0.72(0.13-3.82)$ & $0.70(0.13-3.76)$ \\
\hline \multicolumn{5}{|c|}{ Rhabdomyosarcoma ${ }^{\mathrm{e}}(N=40)$} \\
\hline \multicolumn{5}{|c|}{ Highest parental education in household } \\
\hline Long & NA & NA & 1 (Ref.) & 1 (Ref.) \\
\hline Medium & NA & NA & $0.33(0.03-3.23)$ & $0.35(0.04-3.49)$ \\
\hline Short & NA & NA & $2.04(0.24-17.03)$ & $2.16(0.25-18.41)$ \\
\hline
\end{tabular}

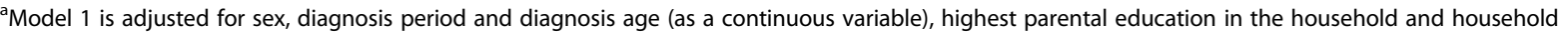
cohabitation status.

${ }^{b}$ Model 2 is adjusted for sex, diagnosis period and diagnosis age (as a continuous variable), highest parental education in the household, household cohabitation status, and additionally adjusted for number of total contacts in the last 24 months before diagnosis (as a continuous variable).

cAdvanced stage: WBC at diagnosis $\geq 100 \times 10^{9} / \mathrm{L}$; Low stage: WBC at diagnosis $<100 \times 10^{9} / \mathrm{L}$

${ }^{\mathrm{d}}$ Advanced stage: Stage 3-4; Low stage: Stage 1-2; ${ }^{\mathrm{e}}$ Advanced stage: Metastases; Low stage: No distant metastases/unknown. For rhabdomyosarcoma, few observations in analyses of cohabitation status and depression, resulted in too uncertain estimates and are not shown

be a barrier for bringing the child to health care services.

Further, we chose to not mutually adjust analyses for all SEP and health variables included in the study, acknowledging that the influence of each factor may be partly overlapping, but also may represent different aspects of socioeconomic resources' influence on health care use. To our knowledge, this is the first assessment of SEP in relation to prediagnostic health care contacts and stage of disease at diagnosis in children with cancer. Using data from the DCCR [32] enabled the application of the Toronto Guidelines to define reasonable and consistent measures of stage in children with certain types of cancer suitable for epidemiological analysis $[43,55]$ although groups are small even in this nationwide study. The guidelines were applicable for most cancer types except for ALL, where we used WBC as a proxy of stage $[30,56]$. As the available clinical data was not always complete, accessing patient files would have provided us with more complete and accurate data to assign stage [43]. It would also have enabled us to assign stage of CNS tumors since particularly for CNS tumors sufficient information was not available from the DCCR. On the other hand, the DCCR is a comprehensive register evaluated yearly and the completeness is estimated to be $100 \%$ for children < 15 years of age at diagnosis since 2003 [32]. We have no reason to believe that 
missing information on stage was associated with SEP. As childhood cancer is a group of heterogeneous diseases, numbers of children in each subgroup are low reducing power even in a nationwide cohort, and at the same time we carried out a number of analyses thus chance findings cannot be ruled out. We therefore apply emphasis on patterns of estimates rather than focusing solely on the statistically significant findings.

Our findings indicate that family circumstances like parental education, affiliation to the work market, and depression are associated with increased overall utilization of the health care system before diagnosis of childhood cancer while additionally to these SEP indicators also being of non-Western origin was associated with increased utilization of acute health care. Reassuringly, we found no evident association between indicators of SEP and stage of disease among the investigated cancer types. Further research is needed in order to identify how targeted interventions can be implemented to support certain families who struggle to navigate through the health care system and are at a higher risk of experiencing less optimal prediagnostic trajectories. In future studies, more attention should be given to understanding the specific challenges these groups may experience when navigating through the health care system and their specific needs should be addressed. Finally, the long-term impact of those interventions on survival from childhood cancer should be evaluated.

Achieving timely diagnosis is dependent on early referral to secondary care. There may be a potential for reducing the number of contacts and the time to diagnosis by ensuring support for families who struggle to navigate through the health care system when their child is sick. Clinicians should pay attention to an increase in contact frequency as frequent contacts may be associated with childhood cancer [52] or other severe diseases [57]. Awareness campaigns such as Head Smart targeted parents and clinicians have proven successful in reducing time to diagnosis of brain cancer [58] and may also be considered for other cancer types. In general, communication material with instructions about diagnostic procedures, disease and treatment should however, be developed with awareness of differences in health literacy and cultural background in mind.

\section{Supplementary Information}

The online version contains supplementary material available at https://doi. org/10.1186/s12885-021-08837-x.

Additional file 1: Supplementary Table 1 Number of all contacts and emergency contacts to the health care system in children diagnosed with cancer $0-24$ months before diagnosis by time before diagnosis and diagnostic group.

\section{Acknowledgements}

The authors are grateful to Tatiana Hansen for her technical support with data management.

\section{Authors' contributions}

LHP, SOD, KS, FE, LLH and GLA were involved in study design and prepared the statistical analysis plan. GLA analyzed the data. LHP, SOD, KS, FE, LLH, HBL, JFW and GLA interpreted the data. LHP drafted the manuscript. LHP, SOD, KS, FE, HBL, JFW and GLA reviewed the drafts. All authors approved the final manuscript and agreed to be accountable for all aspects of the work.

\section{Funding}

This work was supported by The Danish Childhood Cancer Foundation, The Dagmar Marshalls Foundation, Helsefonden, Else og Mogens Wedell Wedellborgs Foundation and Tømrermester Jørgen Holm og Hustru Elisa f. Hansens Mindelegat. This work is part of Childhood Oncology Network Targeting Research, Organisation \& Life expectancy (CONTROL) and supported by the Danish Cancer Society (R-257-A14720) and the Danish Childhood Cancer Foundation (2019-5934).

\section{Availability of data and materials}

The data that support the findings of this study were accessed remotely on a secure platform at Statistics Denmark. Any access to data requires permission from Statistics Denmark and the Danish Cancer Society: Danish Cancer Society Research Center, Strandboulevarden 49, 2100 Copenhagen, Denmark. Contact Person: Professor Susanne Oksbjerg Dalton. Email: sanne@cancer.dk.

\section{Declarations}

\section{Ethics approval and consent to participate}

No ethics approval nor informed consent were required for this registrybased study in accordance with the Danish Act on Research Ethics Review of Health Research Projects section 14 where it is stated that 'notification of questionnaire surveys and medical database research projects to the system of research ethics committee system is only required if the project involves human biological material'.

Permissions for data linkage were obtained from the Danish Clinical Quality Program - National Clinical Registries (j. no. DBCR-2018-12-13) and the National Board of Health (j. no. 707571) and the project was registered in the Research Registry at the Danish Cancer Society Research Center (2018-DCRC0053). The data used were accessed remotely on the Danish Cancer Society's secure platform at Statistics Denmark. The study was performed in accordance with the Declaration of Helsinki.

\section{Consent for publication}

Not applicable, since no individual person's data was used.

\section{Competing interests}

The authors declare no competing interests.

\section{Author details}

'Department of Paediatrics and Adolescent Medicine, Rigshospitalet, Copenhagen, Denmark. ${ }^{2}$ Survivorship and Inequality in Cancer, Danish Cancer Society Research Center, Copenhagen, Denmark. ${ }^{3}$ Division of Childhood Cancer Epidemiology, Institute for Medical Biostatistics, Epidemiology and Informatics (IMBEI), Johannes Gutenberg University Mainz, Mainz, Germany. ${ }^{4}$ Statistics and Data Analysis, Danish Cancer Society Research Center, Copenhagen, Denmark. ${ }^{5}$ Institute of Clinical Medicine, University of Copenhagen, Copenhagen, Denmark. ${ }^{6}$ Childhood Cancer, Danish Cancer Society Research Center, Copenhagen, Denmark. ${ }^{7}$ Department of Clinical Oncology \& Palliative Care, Zealand University Hospital, Naestved, Denmark.

Received: 22 February 2021 Accepted: 30 September 2021

Published online: 14 October 2021

References

1. Gatta G, Botta L, Rossi S, Aareleid T, Bielska-Lasota M, Clavel J, et al. Childhood cancer survival in Europe 1999-2007: results of EUROCARE-5-a 
population-based study. Lancet Oncol. 2014;15(1):35-47. https://doi.org/10.1 016/S1470-2045(13)70548-5.

2. Wolfe I, Thompson M, Gill P, Tamburlini G. M B, van den Bruel a, et al. health services for children in western Europe. Lancet. 2013;381(9873):1224-34. https://doi.org/10.1016/S0140-6736(12)62085-6.

3. Mogensen H, Modig K, Tettamanti G, Erdmann F, Heyman M, Feychting M. Survival after childhood Cancer-social inequalities in high-income countries. Front Oncol. 2018 Oct 31;8:485. https://doi.org/10.3389/fonc.2018.00485.

4. Gupta S, Wilejto M, Pole JD, Guttmann A, Sung L. Low socioeconomic status is associated with worse survival in children with cancer: a systematic review. PLoS One. 2014;9(2):e89482. https://doi.org/10.1371/journal.pone. 0089482.

5. Simony SB, Lund LW, Erdmann F, Andersen KK, Winther JF, Schüz J, et al. Effect of socioeconomic position on survival after childhood cancer in Denmark. Acta Oncol. 2016;55(6):742-50. https://doi.org/10.3109/0284186X.2 016.1144933.

6. Mogensen H, Modig K, Tettamanti G, Talbäck M, Feychting M. Socioeconomic differences in cancer survival among Swedish children. Br J Cancer. 2016;114(1):118-24. https://doi.org/10.1038/bjc.2015.449.

7. Syse A, Lyngstad TH, Kravdal O. Is mortality after childhood cancer dependent on social or economic resources of parents? A population-based study. Int J Cancer. 2012;130(8):1870-8. https://doi.org/10.1002/ijc.26186.

8. Tolkkinen A, Madanat-Harjuoja L, Taskinen M, Rantanen M, Malila N, Pitkäniemi J. Impact of parental socioeconomic factors on childhood cancer mortality: a population-based registry study. Acta Oncol. 2018;57(11):1547-55. https://doi.org/10.1080/0284186X.2018.1478125.

9. Erdmann F, Winther JF, Dalton SO, Zeeb H, Krøyer A, Bautz A, et al. Survival from tumours of the central nervous system in Danish children: is survival related to family circumstances? Int J Cancer. 2018;142(4):671-80. https:// doi.org/10.1002/ijc.31082.

10. Adam M, Rueegg CS, Schmidlin K, Spoerri A, Niggli F, Grotzer M, et al. Socioeconomic disparities in childhood cancer survival in Switzerland. Int J Cancer. 2016;138(12):2856-66. https://doi.org/10.1002/ijc.30029.

11. Erdmann F, Winther JF, Dalton SO, Lightfoot $T$, Zeeb H, Simony SB, et al. Survival from childhood hematological malignancies in Denmark: is survival related to family characteristics? Pediatr Blood Cancer. 2016;63(6):1096-104. https://doi.org/10.1002/pbc.25950.

12. Patterson J, Holm K. The impact of childhood cancer on the family: a qualitative analysis of strains, resources, and coping behaviors. Psychooncology. 2004;13(6):390-407. https://doi.org/10.1002/pon.761.

13. Holm K, Patterson J. JG gurney. Parental involvement and family-centered care in the diagnostic and treatment phases of childhood cancer: results from a qualitative study. J Pediatr Oncol Nurs. 2003;20(6):301-13. https://doi. org/10.1177/1043454203254984.

14. Gage-Bouchard EA, Devine KA, Heckler CE. The relationship between sociodemographic characteristics, family environment, and caregiver coping in families of children with cancer. J Clin Psychol Med Settings. 2013;20(4):478-87. https://doi.org/10.1007/s10880-013-9362-3.

15. Bhatia S. Disparities in cancer outcomes: lessons learned from children with cancer. Pediatr Blood Cancer. 2011;56(6):994-1002. https://doi.org/10.1002/ pbc.23078.

16. Dixon-Woods M, Findlay M, Young B, Cox H, Heney D. Parents' accounts of obtaining a diagnosis of childhood cancer. Lancet. 2001;357(9257):670-4. https://doi.org/10.1016/S0140-6736(00)04130-1.

17. Abbe M, Simon C, Angiolillo A, Ruccione K, Kodish ED. A survey of language barriers from the perspective of pediatric oncologists, interpreters, and parents. Pediatr Blood Cancer. 2006;47(6):819-24. https://doi.org/10.1002/pbc.20841.

18. Ahrensberg JM, Schrøder H, Hansen RP, Olesen F, Vedsted P. The initial cancer pathway for children - one-fourth wait more than 3 months. Acta Paediatr. 2012;101(6):655-62. https://doi.org/10.1111/j.1651-2227.2012.02625.x.

19. Abrahamsen CF, Ahrensberg JM, Vedsted P. Utilisation of primary care before a childhood cancer diagnosis: do socioeconomic factors matter?: a Danish nationwide population-based matched cohort study. BMJ Open. 2018;8(8):e023569. https://doi.org/10.1136/bmjopen-2018-023569.

20. Ahrensberg JM, Fenger-Grøn M, Vedsted P. Use of primary care during the year before childhood cancer diagnosis: a nationwide population-based matched comparative study. PLoS One. 2013;8(3):e59098. https://doi.org/1 0.1371/journal.pone.0059098.

21. Dommett RM, Pring H, Cargill J, Beynon P, Cameron A, Cox R, et al. Achieving a timely diagnosis for teenagers and young adults with cancer: the ACE "too young to get cancer?" study. BMC Cancer. 2019;19:1-15.
22. Austin MT, Hamilton E, Zebda D, Nguyen H, Eberth JM, Chang Y, et al. Health disparities and impact on outcomes in children with primary central nervous system solid tumors. J Neurosurg Pediatr. 2016;18(5):585-93. https://doi.org/10.3171/2016.5.PEDS15704.

23. Hamilton EC, Nguyen HT, Chang Y-C, Eberth JM, Cormier J, Elting LS, et al. Health disparities influence childhood melanoma stage at diagnosis and outcome. J Pediatr. 2016;175:182-7. https://doi.org/10.1016/j.jpeds.2016.04.068.

24. Youlden DR, Frazier AL, Gupta S, Pritchard-Jones K, Kirby ML, Baade PD, et al. Stage at diagnosis for childhood solid cancers in Australia: a populationbased study. Cancer Epidemiol. 2019;59:208-14. https://doi.org/10.1016/j.ca nep.2019.02.013

25. Brasme J-F, Morfouace M, Grill J, Martinot A, Amalberti R, Bons-Letouzey C, et al. Delays in diagnosis of paediatric cancers: a systematic review and comparison with expert testimony in lawsuits. Lancet Oncol. 2012;13(10): e445-59. https://doi.org/10.1016/\$1470-2045(12)70361-3.

26. Pritchard-Jones K, Graf N, Van Tinteren H, Craft A. Evidence for a delay in diagnosis of Wilms' tumour in the UK compared with Germany: implications for primary care for children. Arch Dis Child. 2016;101(5):417-20. https://doi. org/10.1136/archdischild-2015-309212.

27. Truong B, Green AL, Friedrich P, Ribeiro KB, Rodriguez-Galindo C. Ethnic, racial, and socioeconomic disparities in retinoblastoma. JAMA Pediatr. 2015; 169(12):1096-104. https://doi.org/10.1001/jamapediatrics.2015.2360.

28. Garner EF, Maizlin II, Dellinger MB, Gow KW, Goldfarb M, Goldin AB, et al. Effects of socioeconomic status on children with well-differentiated thyroid cancer. Surgery. 2017;162(3):662-9. https://doi.org/10.1016/j.surg.2017.04.008.

29. Offor UT, Basta NO, James PW, McNally RJQ. Is there a socioeconomic variation in survival from renal tumours in children and young people resident in northern England (1968-2012)? Cancer Epidemiol. 2017;50(Pt A): 92-8. https://doi.org/10.1016/j.canep.2017.08.010.

30. Njoku K, Basta N, Mann KD, McNally RJQ, Pearce MS. Socioeconomic variation in survival from childhood leukaemia in northern England, 1968-2010. Br J Cancer. 2013;108(11):2339-45. https://doi.org/10.1038/bjc.2013.222.

31. Pedersen CB. The Danish civil registration system. Scand J Public Health 2011;39(7):22-5. https://doi.org/10.1177/1403494810387965.

32. Schroeder H, Rechnitzer C, Wehner P, Rosthøj S, Møller JK, Lausen B, et al. Danish childhood Cancer registry. Clin Epidemiol. 2016;8:461-4. https://doi. org/10.2147/CLEP.S99508.

33. Steliarova-Foucher E, Stiller C, Lacour B, Kaatsch P. International classification of childhood cancer, third edition. Cancer. 2005;103(7):1457-67. https://doi. org/10.1002/cncr.20910

34. Petersson F, Baadsgaard M, Lau, Thygesen C. Danish registers on personal labour market affiliation. Scand J Public Health. 2011;39(7):95-8. https://doi. org/10.1177/1403494811408483.

35. Baadsgaard M, Quitzau J. Danish registers on personal income and transfer payments. Scand J Public Health. 2011;39(7):103-5. https://doi.org/10.11 77/1403494811405098.

36. Jensen VM, Rasmussen AW. Danish education registers. Scand J Public Health. 2011;39(7):91-4. https://doi.org/10.1177/1403494810394715.

37. Galobardes B, Shaw M, Lawlor DA, Lynch JW, Davey SG. Indicators of socioeconomic position (part 1). J Epidemiol Community Health. 2006;60(1): 7-12. https://doi.org/10.1136/jech.2004.023531.

38. Charlson ME, Pompei P, Ales KL, MacKenzie CR. A new method of classifying prognostic comorbidity in longitudinal studies: development and validation. J Chronic Dis. 1987;40(5):373-83. https://doi.org/10.1016/0021-9681(87)90171-8.

39. Lynge E, Lynge Sandegaard J, Rebolj M. The Danish National Patient Register. Scand J Public Health. 2011;39(7):30-3. https://doi.org/10.1177/14 03494811401482

40. Mors O, Perto GP, Preben \&, Mortensen BO. The Danish Psychiatric Central Research Register. Scand J Public Health 2011;39(7):54-57, DOl: https://doi. org/10.1177/1403494810395825.

41. Kildemoes HW, Sørensen HT, Hallas J. The Danish National Prescription Registry. Scand J Public Health. 2011;39(7):38-41. https://doi.org/10.1177/14 03494810394717.

42. Sahl Andersen J, De Fine ON, Krasnik A. The Danish National Health Service Register. Scand J Public Health. 2011;39(7):34-7. https://doi.org/10.1177/14 03494810394718

43. Gupta S, Aitken JF, Bartels U, Brierley J, Dolendo M, Friedrich P, et al. Paediatric cancer stage in population-based cancer registries: the Toronto consensus principles and guidelines. Lancet Oncol Lancet Publishing Group. 2016;17(4):e163-72. https://doi.org/10.1016/S1470-204 5(15)00539-2 
44. Verlinde E, De Laender N, De Maesschalck S, Deveugele M, Willems S. The social gradient in doctor-patient communication. Int J Equity Health. 2012; 11(1):12. https://doi.org/10.1186/1475-9276-11-12.

45. Gage E. Examining the most relevant conceptualization of the socioeconomic status construct for cancer research. Cancer Nursing [Internet]. 2010;33(3):E1-9 [cited 2018 mar 14] Available from: http://www. ncbi.nlm.nih.gov/pubmed/20357651.

46. Clarke RT, Jones CH, Mitchell CD, Thompson MJ. 'Shouting from the roof tops': a qualitative study of how children with leukaemia are diagnosed in primary care. BMJ Open. 2014;4(2):e004640.

47. Pedersen LH, Wahlberg A, Cordt M, Schmiegelow K, Dalton SO, Larsen HB, Parent's perspectives of the pathway to diagnosis of childhood cancer: a matter of diagnostic triage. BMC Health Serv Res. 2020;20(1):969. https://doi. org/10.1186/s12913-020-05821-2.

48. Abel T. Cultural capital and social inequality in health. J Epidemiol Community Health. 2008;62(7):e13. https://doi.org/10.1136/jech.2007.066159.

49. Center for Sundhed - Enhed for Tværsektoriel Udvikling. Børns brug af regionalse sundhedsydelser - En registeranalyse i Region Hovedstaden [Internet]. [cited 2020 Jun 15]. Available from: www.healthnavigator.se

50. Social- og Indenrigsministeriets Benchmarkingenhed. Småbørnenes akutte kontakter til sundhedsvaesenet [Internet]. 2019 [cited 2020 Jun 15]. Available from: www.simb.dk

51. Lyngsøe BK, Rytter D, Munk-Olsen T, Vestergaard CH, Christensen KS, Bech $\mathrm{BH}$. Maternal depression and primary healthcare use for children: a population-based cohort study in Denmark. Br J Gen Pract. 2019;69(680): E182-9. https://doi.org/10.3399/bjgp18X700733.

52. Dommett RM, Redaniel MT, Stevens MCG, Hamilton W, Martin RM. Features of childhood cancer in primary care: a population-based nested casecontrol study. Br J Cancer. 2012;106(5):982-7. https://doi.org/10.1038/bjc.2 011.600 .

53. Ahrensberg JM, Hansen RP, Olesen F, Schrøder H, Vedsted P. Presenting symptoms of children with cancer: a primary-care population-based study. Br J Gen Pract. 2012;62(600):e458-65. https:/doi.org/10.3399/bjgp12X652319.

54. Thygesen LC, Daasnes C, Thaulow I, Brønnum-Hansen H. Introduction to Danish (nationwide) registers on health and social issues: structure, access, legislation, and archiving. Scand J Public Health. 2011;39(7):12-6. https://doi. org/10.1177/1403494811399956.

55. Aitken JF, Youlden DR, Moore AS, Baade PD, Ward LJ, Thursfield VJ, et al. Assessing the feasibility and validity of the Toronto childhood Cancer stage guidelines: a population-based registry study. Lancet Child Adolesc Health. 2018;2(3):173-9. https://doi.org/10.1016/S2352-4642(18)30023-3.

56. Toft N, Birgens $H$, Abrahamsson J, Bernell P, Griškevičius L, Hallböök $H$, et al. Risk group assignment differs for children and adults $1-45$ yr with acute lymphoblastic leukemia treated by the NOPHO ALL-2008 protocol. Eur J Haematol. 2013;90(5):404-12. https://doi.org/10.1111/ejh.12097.

57. Hauswaldt J, Hummers-Pradier E, Himmel W. Does an increase in visits to general practice indicate a malignancy? BMC Fam Pract. 2016;17(1):94 https://doi.org/10.1186/s12875-016-0477-0.

58. Walker D, Liu J, Merphy L, Wilne S. Delayed diagnosis of paediatric brain tumours - HEADSMART be brain tumour aware (www.headsmart.org.uk). Arch Dis Child. 2016;101(Suppl 1):A212.2-A212. https://doi.org/10.1136/a rchdischild-2016-310863.351.

\section{Publisher's Note}

Springer Nature remains neutral with regard to jurisdictional claims in published maps and institutional affiliations.

Ready to submit your research? Choose BMC and benefit from:

- fast, convenient online submission

- thorough peer review by experienced researchers in your field

- rapid publication on acceptance

- support for research data, including large and complex data types

- gold Open Access which fosters wider collaboration and increased citations

- maximum visibility for your research: over $100 \mathrm{M}$ website views per year

At BMC, research is always in progress.

Learn more biomedcentral.com/submissions 